Gustavo Illades

\title{
Diálogo sobre Anfitrión entre Fernando de Rojas y Francisco de Villalobos
}

El presente escrito es parte de una investigación que propone un sistema de correspondencias entre La Celestina y las obras del médico y polígrafo Francisco de Villalobos; dichas obras son médicas ( $\mathrm{Su}$ mario de la medicina, Salamanca, 1498), de filosofía natural y moral (por ejemplo, las Sentencias) y también misceláneas. A partir de la noción científica de amor hereos, las correspondencias abarcan diversos aspectos literarios: temáticos, estilísticos, genéricos y, sobre todo, cstéticos, pues una poética 'tragicómica' atrae hacia sí la totalidad de los materiales utilizados por autores afines, asimismo, en cuestiones biográficas (Femando de Rojas y Villalobos, ambos de origen judío, estudiaron juntos en la Universidad de Salamanca). La explicación de dichas correspondencias me llevo a proponer una hipotesis según la cual La Celestina y las obras del médico —entre otras posibles — fueron productos textuales de un "taller salmantino", productos que derivaron de un amplio coloquio cntre estudiantes conversos asociados. Mientras que la hipótesis del "taller" supuso reconstruir -o construir — diferentes diálogos entre las obras y los autores mencionados, el planteamiento de los diálogos implics discurrir sobre tres aspectos fundamentales de La Celestina que la crítica ha tratado por separado: la dimensión semántica, cl género y la pluriautoría (propongo a Villalobos como probable autor del Primer Auto). 
En la biblioteca de Rojas figuraba un libro cuyo título fue transcrito o simplemente aludido como Anfitrion en el testamento del bachiller. Este documento lo publicó la Revista de Filología Española en el año 1929 con unas "Notas de la Redacción" en las cuales "se intenta identificar los libros de romance citados en el inventario de los bienes de Fernando de Rojas". A la obra de Plauto se le identifica con la Muestra de la lengua castellana en el nacimiento de Hercules o Comedia de Amphitrion, traducida por Fernán Pérez de Oliva hacia 1525. ${ }^{1}$ Nada demuestra $\mathrm{el}$ aserto, que ha sido reproducido acríticamente por estudiosos de los libros propiedad de Rojas como Gilman. ${ }^{2}$ Cabc recordar que Francisco de Villalobos publicó su traducción de la obra plautiana - la primcra al castellano- hacia 1515. El diálogo que propongo entre el bachiller y el médico tiene el propósito ulterior de resolver el problema sobre cuál de las dos versiones se hallaba en la biblioteca de Rojas. Ello requiere someter a examen la mención cuasi retórica que Proaza hace del comediógrafo latino, la elección del anómalo término tragicomedia - con el cual Plauto, y a la zaga Rojas, intitulan sus asimismo anómalos textos-y las versiones castellanas del libro - Anfitrion- que, entre otros cuarenta y ocho escritos "en romance", Rojas hercdó a su esposa Leonor Álvarez el 3 dc abril de 1541.

\section{Los versos de Alonso de Proaza}

No debuxó la cómica mano

de Nevio ni Plauto, varones prudentes, tan bien los engaños de falsos sirvientes y malas mugeres, en metro romano.

1 Verase Femando del Valle Lersundi, "Testamento de Femando de Rojas, autor de la Celestina". Revisia de Filología Fispallola. XVI. 1929. pp. 366-388.

2 Véase Siephen Gilman, La España de Fernando de Rojas. Panorama inte. lectual y social de "la Ciclestina", 1978, pp. 416 y ss.; cn adclante. Gilman. La España. 
Cratino y Menandro y Magnes anciano

esta materia supieron apenas

pintar en estilo primero de Athenas.

como este pocta en su castellano. ${ }^{3}$

Quizá para destacarlo, Proaza sitúa el nombre de Plauto entre autoridades anodinas ${ }^{4}$ y omite cl de Terencio. En el otro extremo del libro, los versos acrósticos caracterizan "la obra presente" (que pasó a ser, según Rojas, el Primer Auto de la Comedia de Calisto y Melibea $)^{5}$ como "terenciana obra" y, por lo mismo, única "en lengua común vulgar castellana". La invocación a ambas autoridades habría tenido un propósito común: declarar que La Celestina desciende en línea directa de la comoedia romana. Pero la mención diferenciada de aquéllas parece comunicar algo más.

Al traer a cuento el Prólogo de Pedro Manuel Jiménez de Urrea a su Penitencia de amor, una de las primeras imitaciones de la Celestina, Lida de Malkiel (La originalidad, pp. 29-30) aclara el sentido de la expresión "terenciana obra" durante los siglos xv y xvl: 'drama de asunto amoroso'. Por su parte, la referencia a "la cómica mano" de Plauto aludiría a otros aspectos de la ascendencia latina de la obra de Rojas. La caracterización de las comedias terencianas y plautianas y su difusión y recepción en España así lo indican, según veremos adelante. Los versos dc Proaza, sin duda, fueron hechos cada uno a propósito; tanto, que semejan labor al alimón con Rojas, como lo muestran la sincronía entre la composición del acróstico y su descubrimiento o la

3 Véase Femando de Rojas, Comedia o Tragicomedia de Calisto y Melibea, cd. de Peter E. Russcll, 1991, pp. 612.613. En adclante, La Celestina.

4 En su edición, Russell dedica tres notas a dichos versos, cn las cualcs co. menta el hecho de que sc conservan sólo fragmentos dc las comedias de Ncvio, Cratino y Mcnandro. y de Magnes únicamente el nombrc. María Rosa Lida de Malkiel habia ya argumentado en el mismo sentido; cf. La originalidad artstica de "la Celestina". 1970. p. 29: en adclante, Lida, La originalidad.

s Se trata de la edición de Toledo (1500), la misma en que aparecen los versos de Proaza. 
reciprocidad de las instrucciones para leer en voz alta cl diálogo con la dimensión dramática de éste.

Encabczada por Castro Guisasola, la crítica moderna cstá de acuerdo en que las comedias de Tcrencio influyeron a la Celeslina más hondamente que las plautianas. ${ }^{6}$ Se remonta la genealogía de los análisis hasta el Comentario a Terencio de Elio Donato, quien elogia en la obra del comediográfo los siguientes aspectos: la hechura de los personajes —en cuanto a su forma de presentación, edad, función, orden y grado de participación-, la inclusión — por afán realista — de merctrices, el reducido número - por afán de claridad - de personajes, el hecho de que éstos nunca se dirigen hacia el público, cl sometimiento de la obra a los límitcs mcdios de la comedia - un tono elevado rozaría la tragedia; uno bajo, al burdo mimo-, en fin, la exclusión de elementos abstrusos e históricos. ${ }^{7}$ Los elogios de Donato a los aciertos terencianos funcionan al mismo tiempo como censuras a los desacicrtos de Plauto. Sin discrepar de Donato, y siguiendo de cerca a Castro Guisasola y Lida, Russell ("Introducción", pp. 38 y ss.) enlista, poco más o menos, las hucllas terencianas en $\mathrm{La}$ Celestina: el incipif moralizante, el Argumento General - los periochae o resúmenes sucintos fueron añadidos a los textos terencianos en el siglo it a. C.-, el Prólogo —Prologus latino innovado por Terencio-, los nombres de algunos personajes

${ }^{6}$ La comedia romana, en especial la de Terencio, fuc para La Celesina modelo directo o indirecto de numerosos resortes lécnicos — tipos de acolación, diálogo. monólogo, aparte, ironía, modos de representación cspacial y temporal-. fijó las catcgorías de varios personajes - enamorados. padrcs, sirvicntes, rameras-. impuso el amor como tema central y dejo huclla langible ca algunas situaciones c incontables sentencias y ecos ycrbales (Lida, La originalidad, 30). De conformidad con lo anterior, Russell ("Introducción" a Femando de Rojas, Comedia 0 Tragicomedia de Calisto y Melibea, 1991. p. 40; en adelante, Russell, "Introducción") nola otros aspectos: destac6 uno comán a Terencio, Plauto, el autor anonimo del Primcr Auto y Rojas: la ausencia de huellas que delaten la región o ciudad donde aconlece la accior. De su lado, Lida intenta demostrar, refutando a Bonilla. Mcnendcz Pelayo y Castro Guisasola, que la comedia romana no influyo cu cl asunto. tono afectivo. pintura de caracteres ni ambiente de la Cclestina.

"Véase Mereedes González-Haba. "Introducción" a Plauto. Comedias, I. 1992. p. 15: en adelante, González-1laba, "Introducción". 
-Scmpronio, Pármeno, Sosia, Crito-, su elocuencia, ${ }^{8}$ su presentación en parcjas que desempeñan el mismo oficio, pero que tienen personalidades diferentes - Sempronio-Pármeno, EliciaArcúsa, Tristán-Sosia—, la creación de cstereotipos —el amoamante irreflexivo, el servus fallax, astuto, hablador, atrevido, controlador de la intriga, el servus fidelis-y la alta tensión dramática resultante del número reducido de personajes, el cual oscila entre diez y catorce.

El esquematismo y mesura de la comedia terenciana la elevaron a modelo natural del arte dramático. Los autores de $\mathrm{La}$ Celestina aprovecharon su estructura -incipit, argumento, diálogos - y la tipología de los personajes, es decir, adoptaron, sobre todo, la dimensión abstracta del modelo. En cambio, Plauto proveyó la factura de un arte atípico y desmesurado cuyo potencial scmántico servía mejor a los propósitos de los autores españoles. Prólogos de dudosa autenticidad, ${ }^{9}$ argumentos en versos acrósticos, ${ }^{10}$ ausencia de didascalias paratextuales, ${ }^{11}$ lenas con-

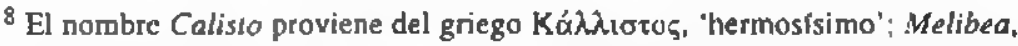
en griego, "vale tanto como dulçura de la vida" (véase Sebastián de Covarnubias. Tesoro de la Lengua Castellana o Española. 1984); Celestina proviene del latín scelestus, 'malvado', 'canalla', aunque sus origencs pucden ser más complejos; el nombre Pleterio presenta relación con la palabra latina plebeius, 'plebeyo'

${ }^{9}$ En la autenticidad dudosa subyace el prablema de la pluriautoría, ta cual se hace patente en cl hecho de que los prólogos a las comedias plautianas retieren el nombre del autor $y$ a veces también el título dcl original griego utilizado (González.Haba. "Introducción", pp. 11-12). Desde esta perspectiva, las alusiones de Rojas a Cota y Mena. y la inclusión del Primer Auto en calidad de obra ajena. pueden verse (asf lo habrian hecho los lectores de la época) como la f́cliz actualización de un modelo clásico. debajo de la que, sin embargo. se cumplía un proposito de indole vital: diluir la identidad de los autores.

${ }^{10}$ La costumbre de revelas en acróstico el nombre del autor "es una práctica medicval frecuente en imitadores y refundidores para dar a conocer su incompleta autoría. y frecuente también en autores que cscriben para un estrecho círculo literario a quicn su nombre no es desconocido. circunstancias ambas que cuadran no. tablemente con lo que se sabe de Rojas" (Lida, La originalided, p. 15). Lida cnlista ejemplos europeos medievalcs: cl único caso cspafiol que refiere cs cl dc las Partidas (allf el nombre de Alfonso el Sabio cstá formado por las letras iniciales de cada capítulo). Desde mi perspectiva, cl recurso al acróstico completa cl procedimiento y el objetivo de Rojas apuntados en la nota anterior.

11 Dicha ausencia, que incluyc clementos lingursticos -cualidad de la voz, 
sejeras dadas a la embriaguez ${ }^{12}$ son aspectos de una producción cómica que el anónimo y Rojas rcelaboraron a fondo. En las censuras de Elio Donato reluce la originalidad del comediógrafo latino: Plauto hace hablar a los personajcs con el público, incluye temas históricos y fuerza los límites de la comedia porque da voz a dioses y hombres graves. Invocando la Poética de Aristóteles, Russell ("Introducción", p. 43) hace un reproche diríamos donatiano a los autores de La Celestina por caer en la contradicción fundamental que supone "el compromiso a contar la historia de unos amores aristocráticos y cl hecho de que el instrumento escogido para hacerlo [la comoedia] es una forma literaria creada para dibujar escenas de la vida burguesa".

De la comedia plautiana proceden asimismo vivaces descripciones de oficios (piénsese en el curriculum vitae de Celestina tararcado por Pármeno en cl Primer Auto) y bocetos de personajes femeninos atípicos (la enamorada Selenia de la Cistellaria, por cjemplo). Pero si algún aspecto de su originalidad atañe a La Celestina, éstc es la composición de diálogos con amplia gama de registros discursivos, los cuales aportan ambigüedad a los personajes, si bien en el caso de Plauto los registros expresan los rasgos más aparentes de aquéllos, así el estrato social o la edad (González-Haba, "Introducción", pp. 22-23). Germen de multiplicidad de significados y sentidos, esta variedad dialógica de la palabra mal soporta el trazo de estcreotipos, pues la subjetividad de los personajes corre pareja con su original elocuencia; de ahí que ni Plauto ni cl anóni-

cntonación, etc.- y paralinguírticos - gestos, características de los personajes como edad o vestimenta, lugar y ambiente de la ficción literaria-, es propia de las comedias de Plauto, no de las terencianas (Gonźllez-Haba, "Introducción", p. 30).

12 Según Castro Guisasola (Obsenaciones sobre las fuentes titeraricas de "la Celestina", 1924. p. 53), que minimiza la influcncia del comediografo latino en la Celestina, Plauto es quien mejor definc los caracteres de tipo celestinesco; Cisteltaria (1, 1) y Curculio (1, 1-2) piesentan alcahuctas que. a difcrencia de la Urraca del Arciprestc de Hito, tienen afición al vino. 
mo ni Rojas los hayan utilizado. A la riqueza de la palabra hablada, precisamente, hace referencia Nebrija a la hora de elogiar a Plauto como artista: "Plautus est summus orator ut omnium hominum gestus sciat effingere". Gilman (La España, 310) glosa así el aserto de Nebrija:

Fueron alabanzas como éstas las que asimiló Rojas. Pudo ser escéptico accrca de los bencficios morales de la retórica - Celestina es el orador más convincente de España-, pero estaba claramente fascinado por las potencialidades de la palabra para la creación de nuevos seres humanos.

Los manuscritos, impresos y traducciones españolas de la comedia latina reproducen nuestra imagen de Plauto dcsde otra perspectiva. El panorama es como sigue. ${ }^{13}$

A) Manuscritos en España:

-Siglo xr: dos de Terencio

- Siglo xII: uno de Terencio

-Siglo xiv: scis de Terencio; dos de Plauto

- Siglo xv: veinte de Tcrencio; catorce de Plauto

B) Primeras ediciones latinas en España: ${ }^{14}$

- Siglo xv: una de Terencio (Comoediae cum duobus commentis Aelii Donati et Johannis Calphurnii, Juan Rosenbach, Barcelona, 1498)

-Siglo xvi: una de Plauto (Menechmi cum notis Dionisi Lambini, Salamanca, 1581)

C) Inventario español de libros:

-Siglo xv: treinta copias de Terrencio siue Donalo; una copia de Plauto (Juan Rix, Valencia, octubre de 1490)

13 Para los datos subsiguientes, véase Edwin J. Wcbber, "Manuscripts and Early Printed Editions of Terence and Plautus in Spain", Romance Philology. XI, 1, 1957, pp. 29-39; cn adelanle, Wcbber, "Manuscripts".

14 Webber ("Manuscripts", p. 34) cxplica la escasez de ediciones latinas en Es. paña durante los siglos xv y xvi por la abundante producción y continua exporiación italiana de libros. 
D) Ediciones curopeas:

-1520: ciento setenta y cinco de Terencio; diez y siete de Plauto

E) Primeras traducciones al castellano publicadas en España:

-1517 (y 1544): Francisco de Villalobos traduce Anfitrion $^{15}$

- Hacia 1525: Femán Pérez de Oliva traduce Anfïrión

-1576: Pcdro Simón de Abril, "Terencio, traduzido en castellano"

De los datos anteriores se desprende que la comedia terenciana fue descubierta, estudiada y difundida antes y en mayor escala que la de Plauto, no sólo en España, ${ }^{16}$ sino en Europa. Terencio, podemos dcducir, está más presente que Plauto en la cultura española. Esto es cierto sobre todo para el ámbito académico, como lo nota Russell ("Introducción", p. 38):

las seis comedias de Terencio, debido a la pureza y fluidez conversacional de su latín y a su contenido a la vez divertido y sentencioso, servían con frecuencia durante lá Edad Media y el Renacimiento de libro de texto escolar para los que hacían su aprendizaje en latín.

Pero si se considera el caso particular de Anfitrión, no es excesivo decir que esta obra fue útil indispensable en el instrumental poćtico de escritores abocados a componer en lengua castellana.

15 Webber ("Manuscripts", p. 36), quien no explica la tardía traducción de las comedias terencianas al castellano, afirma que la de Villalobos fue hecha en 1515 y publicada en Alcalá de Henares en 1517; documenta los datos en J. Catalina Garcla, Ensayo de una tipografía complusense (Madrid, 1889). La edición del voluınen misceláneo de 1544 que reficre no cs la princeps: Juan Picardo lo había ya publicado en Zamora el año anterior.

16 En cualquicr caso, ambos comediografos formaban una unidad en cl horizonte clásico de España durante los siglos xv y xvi: "la publicación en 1501 en Salamanca del Philodoxus de Alberti podría indicar que la reglamentación de 1538 a efecto de que sc dedicaran cierios domingos a la representación de una 'Comedia de Plauto o Tcrencio o Tragicomedia' estaba basada en una tradición anterior" (Gilman, La España. p. 308). 
Así lo demuestran La Celestina, la temprana traducción de Villalobos, que influyó por vía directa al Amphitrión de Juan Timoneda (Webber, "Manuscripts", p. 36), la traducción de Pérez de Oliva y, un siglo después, las ideas dramatúrgicas de Lope de Vega:

Terencio fue más visto en los preceptos, pues que jamás alzó el estilo cómico a la grandeza trágica, que tantos reprehendieron por vicioso en Plauto [...]. ${ }^{13}$

La difusión y recepción españolas de la comedia latina hasta aquí observadas presentan reciprocidad con la idea precedente; a saber, los autores de La Celestina adoptaron lo más abstracto del modelo ("terenciana obra") y la singular hechura de la "cómica mano de Plauto". Si Rojas metió la pluma en los versos de Proaza, lo hizo, entre otras cosas, para diferenciar el ascendiente que en su obra tienen los comediógrafos latinos. Dicho ascendiente incluye, sobre todo, la admirable ocurrencia plautiana de mezclar comedia con tragedia, como veremos a continuación.

\section{Tragicomedia}

El cambio de título de la Comedia de Calisto y Melibea obedeció a un delicado procedimiento de Rojas según el cual éste dejó asomar solapada y paulatinamente la naturaleza de su obra adscribiéndola por derccho propio a un modelo clásico -la tragicomedia de Plauto- y autorizándola en él. Ya hemos anotado dos casos en los que el procedimiento es análogo: las alusiones a Cota y Mena y cl uso de versos acrósticos.

${ }^{17}$ Lope Felix de Vega Carpio, Arte nuevo de hacer comedias, Ouras escogidas, 11. 1961. p. 894. En adelante, Lope. Arte nuevo. 
Veamos ahora cómo argumenta Rojas en su Prólogo el cambio de título:

Otros han litigado sobre el nombre, diziendo que no se avía de llamar comedia, pues acabava en tristeza, sino que se llamase tragedia. El primer autor quiso darle denominación del principio, que fue plazer, y llamóla comedia. Yo, viendo estas discordias, entre estos estremos parti agora por medio la porfía, y llaméla "tragicomedia".

Semejante relato oculta por completo posibles vínculos entrc el autor anónimo y Rojas. Y digo posibles porque en "E] autor a un su amigo" el bachiller comete un desliz por exceso de celo cuando justifica dos veces y con argumentos divergentes cl anonimato del primer autor. ${ }^{18}$ Como no podemos saber si este autor (quien, según Rojas, llamó comedia a un texto incompleto con arranque placentero) dejó alguna indicación acerca del desenlace o la comunicó de cualquier manera al bachiller, ni tampoco es posible explicar por qué no se llamó tragicomedia la edición de 1499 (título consccucnte desde la perspectiva del Prólogo, pues el final cs triste), debemos conformamos con examinar la sola modificación del título, la cual, motivada por "otros [que] han litigado sobre el nombre", otros seres obsesivamente anónimos, responde en apariencia a un criterio argumental (placer/lristeza) y no a uno genérico (comoedialtragoedia). Cabe entonces recordar la historia del tórmino tragicomedia.

Para Aristótcles, "la comedia es [...] imitación de hombres inferiores, pero no en toda la cxtensión del vicio, sino que lo risible es parte de lo feo". De su lado, tragedia "es imitación, no de personas, sino de una acción y de una vida"; "la imitación tiene por objeto no sólo una acción completa, sino tam-

18 "Vi que [no] Icnía su firma del autor, y era la causa que estava por acabar [...].

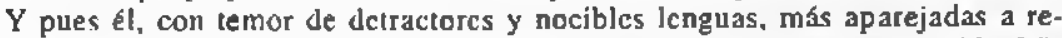
prehender que a saber inventar, [celo] su nombre [...]" (La Celestina, pp. 185-186). 
bién situaciones que inspiran temor y compasion"; "una buena fábula scrá simple antes que doble [...] y no ha de pasar de la desdicha a la dicha, sino, al contrario, de la dicha a la desdicha; no por maldad, sino por un gran yerro, o de un hombre cual se ha dicho [intermedio entre virtuoso y malvado], o de uno mejor antes que pcor". ${ }^{19}$

En el Prólogo a Anfitrión, Plauto cede la palabra al personaje Mercurio, quien así habla a los virtuales espectadores, admirados de que el autor les ofrezca una tragedia:

Pero bueno, ¿qué pasa?, ¿fruncís el ceño porque he dicho que iba a ser una tragedia? Nada, no hay que apurarse, soy un dios, la transformaré; si es que estáis de acuerdo, la volveré de tragedia en comedia sin cambiar un sólo verso [...]. Ya sé lo que os gustaria: haré una mezcla, una tragicomedia; no. es que hacer que sea todo el ticmpo una comedia, viniendo reyes y dioses, la verdad, no me parece ni medio bien. Vamos a ver, como también hay un papel de esclavo, haré que sea una tragicomedia, como acabo de decir. ${ }^{20}$

La intención burlesca de Mercurio debemos contrastarla con el hecho de que Anfirión es la única comedia de Plauto con tema mítico (la leyenda del ciclo tebano sobre el nacimiento de Hércules y circunstancias precedentes), lo cual pesa en el acto final, pues la esclava Bromia hace un recuento de hechos típico de la tragedia. El tema mítico, su desarrollo cómico y el cierre solemne de la obra suponen una mczcla de géneros que cuadra bien con el neologismo de Plauto: tragicomedia. Necesariamente problemática, dicha mezcla retiene mal los preceptos aristotélicos; por ello, el juicio poético del Prólogo se concentra en el estatuto de los personajes.

${ }^{19}$ Aristóteles, Poérica, 1992, pp. 141-142, 147, 161 y 170-171.

20 Plauto, Anfirrión, Comedias 1, 1992, pp. 50-51. En adclante, Plauto, Anfitrión. 
Siglos más tarde, Elio Donato actualizó las ideas de Aristóteles al glosar la comedia terenciana. En su Comentario a Terencio (González-Haba, "Introducción", p. 16), atribuye a la comedia personajes corrientes, conflictos de poca monta, solución feliz, un mundo ligado a la vida y argumentos siempre ficticios. En sentido inverso, atribuye a la tragedia personajes graves, conflictos serios, desenlaces fatales, un mundo ligado a la muerte y argumentos historicos. Describe asimismo un procedimiento que incumbe directamente a La Celestina: "en la comedia, la complicación vienc al principio, al final se soluciona todo; en la tragedia, todo lo contrario". Si, como observa Donato, la comedia tiene una solución feliz a partir de un conflicto, y la tragedia un desenlace fatal o conflictivo a partir de un no conflicto, el plazer y la tristeza que menciona Rojas en su Prólogo (y también en una octava Proaza) ${ }^{21}$ comprometen, además del argumento, la estructura y aun el género de la obra.

Téngase en cuenta que algunos manuscritos de comedias latinas existentes en España contienen, ya glosas, ya comentarios del mismo Donato. Baste referir las Plauti comoediae cum glossis, Ms. 9379 (siglo xv) de la Biblioteca del Real Seminario Sacerdotal de San Carlos, Zaragoza, o las Terentii

\section{1 "IToca cómo sc devfa la obra llamar tragicomedia y no comedia:}

Penados amantes jamás conseguierond de enıpresa tan alta tan prompta victoria/ como éstos de quien recuenta la hystoria, ni sus grandes penas tan bien succedicron.l Mas, como firmeza nunca tovicron los gozos de aqueste mundo traydor./ supplico que llores, discreto lector,/ el trágico fin que todos ovieron.]" Lida obscrva (La originalidad, p. 51), a contracomente de la octava, que el géncro de la obra lo distinguc Proaza (en los versos previos, donde menciona a Plauto y a los comediógrafos gnegos) con base en su forma dramática y no cn su desenlace fatal. Asimismo, obserła que el género cstá especificado cn cl Prólogo ("Asst que, quando dicz. personas se juntaren a oýr csta comedia") y que cl cambio de comedia a tragicomedia fuc una concesion de Rojas a los Iectores desconrentadizos. En mi opinión, los versos acrósticos, los de Proaza y el Prólogo. en lo que toca a la denominación genérica de la obra, presentan correspondencia plena y obedecen a un mismo intento: develar la naturalcza de La Celestina va la declaración de su ascendencia espectficamentc plautiana. 
comoediae cum commento Donati, Ms. 623 (1427) de la Bibliotcca Central de Barcelona (Wcbber, "Manuscripts", pp. 37 y 39). Con seguridad, nuestros autores españoles conocieron las glosas y comentarios a los latinos; así entonces, las referencias al título elegido por el autor anónimo y al cambio y justificación debidos a Rojas apuntan hacia la genealogía genérica de la obra. ${ }^{22}$

A pesar de su importancia, la comedia humanística italiana ${ }^{23}$ no medió la relación entre la Tragicomedia de Rojas y la de Plauto. El caso de Frulovisi, quien, con apego al autor latino, usa el término en sus comedias Claudi duo (1432) y Symmachus (1434), es algo menos remoto a La Celestina que el de

22 No obstante que la Podrica de Anstóteles habia sido traducida al lalín un ра de veces en España - por Hermán Alemán a mediados del siglo xiा y por Mantino de Tortosa en el siglo xiv-, y no obstante que Giorgio Valla habia publicado en 1498, cn Venecia, la primera versión latina con espíritu rcnacentista (véase Valentín Garcia Yebra, "Introducción" a Aristóteles, Poética, 1992, pp. 34-35). la obra del Estagirita, hasta donde se sabe. no es fuentc directa de La Celestina. Conrado Haebler (Bibliografia ibérica del siglo XV, 1903) no registra ninguna cdición de la Poérica en España durante el siglo xv.

${ }^{23}$ Russell, quicn sigue los cstudios de Casas Homs, Lida de Malkicl y Anconio Stauble, hace un inventario de correspondencias entre la comedia humanística ifaliana y la Celestino, advirticndo, de paso, que éstas son ajenas a la comedia latina: sustitución de verso por prosa, lugares comunes del mundo cstudiantil, intento deliberado de dramatizar historias amorosas propias de los cucntos cortos cn prosa de la cpoca. sátira anticlerical mordaz e insistente, diálogo abieno poblado de largos y espaciosos soliloquios, caracteres complejos y originales marcadamente individualizados, tcmporalidad incicrta, ausencia de unidad cspacial (los dos últimos aspcctos derivan del hecho siguiente: se trata de textos escritos para ser oralizados por una sola voz, sin apoyo escénico y actoral). Para documentar sus observaciones, Russell recurre a la Mergarila poefica del alemán Albrecht von Eyb (Nuremberg. 1472), antologia que conlicne fragmentos de tres comedias humanisticas. Además, en la biblioteca de Rojas había un ejemplar de la Margari10. Russell mismo ofrece argumentos contrarios a su tcsis, los cuales, desde mi punto de visıa. pesan más que los favorables: a) la primera edición española de una comcdia humanistica (el Philodoxus de León Battista Alberti, escrito cn verso) fue publicada en Salamanca en el año 1500 ; b) el Prólogo del bachiller Juan de Quirós. quien impartía entonces clases en la Universidad de Salamanca. refiere cl escaso conocimicnto que los cstudiantes salmantinos tenían sobre la comedia humaníslica: c) ni Rojas ni Proazz aluden a csc género de comedia; y d) cl autor del Primer Auto de la Celestina decidió, a diferencia de los humanistas italianos. escribir en lengua vernácula (Russcll. "Introducción", pp. 45-52). 
Marcelino Verardi, cuya obra (Fernandus servatus, Valladolid, 1493) licva un prólogo (de Carlos Verardi, tío de aquél) donde vuelve a aparecer, referido a Plauto, el término tragicomedia. $^{24}$

Lida (La originalidad, p. 52) escribe que el sentido de tragicomedia en el Prólogo de Rojas no corresponde al de Vcrardi y otros humanistas - dignidad del elenco, naturalcza del asunto y desenlace feliz-, pero tampoco al de Plauto - intervención de dioses en una comedia-, sino "al realismo integral de $\mathrm{Ia} \mathrm{Ce}$ lestina que, como la vida, muestra la alternancia de dicha y desdicha y no a peculiaridad alguna en su géncro literario". Esta conclusión deja sucltos los cabos; a saber, la genealogía del título, el género literario - para Ijida, "terenciana obra" - y la naturaleza "realista" de La Celestina. Según los argumentos que he venido dando, cabe esta hipótcsis: Rojas reintituló Tragicomedia su obra porque la naturaleza de la misma corresponde más y mejor a la mezcla de dioses y hombres vulgares que Plauto razona en su Prólogo y lleva a efecto en Anfitrión. Sin embargo, los argumentos de Rojas son donatianos (plazer versus tristeza), lo cual compromete cl géncro de La Celestina. Por lo tanto, perfil genérico, naturaleza y título forman una unidad orgánica, la de un diálogo placentero y triste, conflictivo y fatal entre voces divinas y humanas. Toca ahora discurrir sobre la naturaleza tragicómica de La Celestina desde la perspectiva plautiana: el comercio erótico entre dioses y hombres.

En la investigación antes referida, analizo la cosmovisión tragicómica de Villalobos y Rojas. Caracterizada por la tendencia al sincretismo - vital, lingüístico y literario-, dicha cosmovisión atrae hacia su virtual poética de manera digamos natural la mezcla ideológico-discursiva que supone la comunicación entre un conjunto de personajes cuya nómina puede

24 Feniandus servarus no presenta mezcla de elementos serios y burlescos, ni tiene relación ternática, cstilística o generica con La Celestina. 
distribuirse así: 1) personajes silenciosos pero activos: el Dios cristiano, Cupido y Plutón; 2) personajes elocuentes: $a$ ) seres semidivinos: Cclestina; $b$ ) seres humanos: los nobles (Calisto, Melibea, Alisa y Pleberio), los criados y los individuos de bajos fondos sociales (prostitutas y rufianes).

Asimismo, en dicha investigación intento mostrar la identificación entre el Dios cristiano y Cupido (Dios-Amor), el aspecto demónico (representable por Plutón) ${ }^{25}$ como la otra cara de Dios, la función de Cclestina en cuanto mensajera del Dios-Amor y el deicidio simbólico contenido en las equívocas palabras del planto plebérico. Plebcrio apostrofa al DiosAmor reprochándole un desastre cuya causa eficiente es cl contacto celestinesco entre Calisto y Melibea, dos sujetos cnfermos de amor. A su vez, dicho contacto proviene de la invocación de Cclestina a Plutón. El círculo abierto por ésta lo cierra el apústrofe de Pleberio. Profundamente activos, los dioses de la Tragicomedia de Calisto y Melibea hablan a los seres humanos por boca de Celestina, quien, a semejanza del dios Mcrcurio de Anfitrión, comunica, comercia y alcahuetea a un mismo tiempo. Si el sentido de La Celestina parte de su hcterodoxa comunicación humano-divina y deriva en la desautorización plebérica al Dios cristiano, la invención de Plauto hay que situarla entonces en la génesis de la invención de los autores españolcs. Por derecho propio y con cálculo esmerado, Rojas reintitula la obra como Tragicomedia. En efecto, al adscribirse al modelo latino, implícitamente anuncia a los lectores, a quienes explícitamente pretende satisfacer en el Prólogo, la índole problemática de su creación.

La unidad orgánica que hemos obscrvado entre el perfil genérico - diálogo donde se mezcla comedia con tragedia--, la naturaleza sincrética -comunicación de seres metafísicos con

${ }^{25}$ Para una defensa de la eficacia demónica en la obra de Rojas. véase Pcter E. Russcll. "La magia, Icma integral de la Celestina", cn Temas de "La Celestina" y otros estudios, 1978, pp. 243-276. 
humanos- y el título de La Celestina demuestra su pertinencia y, más todavía, su eficacia literaria en la teoría y práctica dramatúrgicas de Lope de Vega. Sobra aclarar que la singular cosmovisión de Rojas, ya inadvertida, ya inaceptable, tuvo apenas resonancia en la literatura subsiguiente. ${ }^{26}$

En un pasaje de la novela Las fornunas de Diana, Lope recuerda "la tragedia famosa de Celestina". ${ }^{27}$ Por tragedia entiende el dramaturgo, según Lida (La originalidad, p. 56), no la heroica de corte aristotélico, sino una pieza realista con desenlace fatal, ajena a personajes principescos consagrados por los libros, pero abierta a ambientes locales y contemporáneos minuciosamente evocados, los cuales, compuestos en prosa, "dan garantía artística de veracidad". Para Lida, La Dorotea es la genial culminación de una "acción en prosa", cuyo trayecto parte de la variedad individual de hombres y ambientes creada por la comedia humanística, y continúa en la estructura de $L a$ Celestina. El arte prosaico, y por ello realista, de La Dorotea, dice la estudiosa, es el más claro reconocimicnto del género dramático de la obra española.

Ciertamente, es irrefutable la influencia de La Celestina en la obra de Lope; también la reciprocidad entre género literario y discurso prosaico; incluso el realismo ${ }^{28}$ que deriva del uso de la prosa. La variedad de registros discursivos y el retrato detallado

${ }^{26}$ Los continuadores de la Celestina pusieron el acento en el aspecto erótico. En cuanto a la novela picaresca, ésta invirtio las categorlas sociales de los individuos al dignificar seres marginales, pero lo hizo por la vía de aplicar a la letra el código religioso dominante. Siempre original, Cervantes dejó entrever mediante un recurso por demás elocuente - los octosílabos de cabo roto- la cosmovisión sincrética de la obra: "según siente Celesti-, / lihro, en mi opinión. divi-, / si encubriera más lo huma-". CF. El ingenioso hidalgo don Quijote de la Mancha, I, 1987, p. 65.

${ }^{29}$ Lope Félix de Vega Carpio, Novelas a Marcia Leonerda, Obras escogidas II, 1961, p. 1346.

28 Prefiero el término naturalismo, sohre todo si sc aplica para describir la inclusión de costumbres, ambientes y hablas popularcs. El reálismo. como bien lo muestra el arte inaugural del Lazarillo de Tormes, consiste en presentar una fabulación en calidad de acontccimicnto rcal y verdadero. 
de un mundo heteromorfo tienen, sí, como condición necesaria, pero no suficiente, el uso de la prosa. Pero antes que éste, el sincretismo genérico o, mejor aún, cl encuentro dialógico ${ }^{29}$ entrc comedia y tragedia multiplica la matcria literaria, así como las formas de su expresión. No es otro el punto de vista de Lope (Ane nuevo, p. 894), quien transfiere la interacción plautiana entre dioses y hombres a otra actual para él (reyes-plebe):
Elíjase el sujeto, y no se mire
(perdonen los preceptos) si es de reyes, aunque por esto entiendo que el prudente
Felipe, rey de España y señor nuestro, en vicndo un rey en ellas se enfadaba, o fuese el ver que el arte contradice, o que la autoridad real no debe andar fingida entre la humilde plebe.

La libertad de temas (sujetos) se remonta hasta la obra de Plauto; así la estrofa siguiente:

Esto es volver a la comedia antigua,
donde vemos que Plauto puso dioses,
como en su Anfirrión lo muestra Júpiter.

${ }^{29}$ La concordancia dialógíca constituye una unidad de dos o varios elementos que, mantcriendo cualquier tipo de relación entrc ellos, no llcgan nunca a fusionarse ni anularse. Véasc Mijall M. Bajtin, "Para una reelaboración del libro sohre Dostoievski", en Estética de la creación verbal, 1982, pp. 329 y ss. El encuentro dialógico que venimos analizando tiene como punto nodal la relación iragicómica entre dioscs y hombres bajos. Rojas desprende de la misma una lección casi nihilista, lo cual no debe ocultarnos la procedencia de dicha relación: cl lenguaje camavalesco. Familiar a Plauto y a los aulores de La Celessina, el Icnguaje carnavalcsco obedece precisamentc a la logica de las cosas "al revés", de las permutaciones constantes de lo alto y lo bajo; pernutar, poner de cabeza el mundo implica degradar, es decir, uansferir al plano matcrial y corporal lo elevado. cspiritual y absiracto. Al camavalizarsc, la literatura cré géneros inéditos, cxperimentó cambios de sentido y modificá formas cstablecidas. sobre todo en el Renacimiento. Véase Bajtín, La culura popular en la Edad Medio y en el Renacimiento, 1987. pp. 16, 21 y 24. Si observamos La Celestina a través de los géneros litcrarios cómicn-serios espafioles, el libro de buen amor viene a scr su modelo medieval por antonomasia. 
Sabe Dios que me pesa de aprobarlo, porque Plutarco, hablando de Menandro, no siente bien de la comedia antigua.

Mas, pues del arte vamos tan remotos. y en España le hacemos mil agravios, cierren los doctos esta vez los labios.

Lo tragicómico, en suma, crea una variedad tal que, por un lado, "deleita mucho" al público de comedias, y, por otro, imita la belleza inherentc a la variedad del mundo natural:
Lo trágico y lo cómico mezclado,
y Terencio con Séneca, aunque sea
como otro minotauro de Pasífae.
harán grave una parte, otra ridícula;
que aquesta variedad dcleita mucho.
Buen ejemplo nos da Naturaleza, que por tal variedad ticnc belleza.

Como podemos observar, Lope ve en la tragicomedia de Plauto ( $y$, a través de ella, creo yo, en la de Rojas, a pesar de que la llame incidentalmente tragedia), más que un género dramátjco establecido, la géncsis poética de su propia comedia nueva.

Empcñada en demostrar cl género dramático de La Celestina, Lida (La originalidad, pp. 54-56) aduce ejemplos renacentistas $^{30}$ alusivos a la obra. Primero cita un tratado de Luis Vives (De causis cormptarum artium, II, 1531) donde el humanista condena por inmoral la comedia latina y absuelve al

30 Lida trae a cucnto en cl mismo pasaje el Prólogo de Juan Timoneda a Las tres comedias (1559), donde el autor elogia el "cstilo cómico para leer puesto cn prosa" de "los amores de Calisto y Melibea" y la Thebaida, pero reprocha a estas obras no ser aptas para la representación. Timnneda concluye: "considerando yo esto, quize hazer comedias en prosa, de tal manera que fuessen breves y represcntables". Insistiendo en su tcsis, Lida asocia extensión con representabilidad. Picnso que de las palabras de Timoneda La Celestina resulta más un dílogo prosaico con vis cómica, compuesto para ser lefdo, cxtenso y no represcntable, que una pieza dramática inepresentable por extcnsa. 
autor "que en nuestra lengua escribió la tragicomedia Celesti$n a$, pues al proceso de los amores y a aquellos goces voluptuosos enlazó el más amargo final". Luego trae a colación cl Diálogo de la lengua, el cual —afirma ella - "no dice palabra acerca de su género literario, cosa sorprendente si de veras ese género hubiesc constituido una rara novedad". Precisamente - digo yo- por ser un diálogo novedoso — cosa nada extraña en una época de innovaciones artísticas-, Juan de Valdés, autor e interlocutor del Dialogo de la lengua, reproduce el título adoptado por Rojas:

VALDÉS. [...] el juicio de todos dos [autores de Celestina] me satisfaze mucho porque suprimieron a mi ver muy bien y con mucha destreza las naturales condiciones de las personas que introduxcron en su tragicomedia $[\ldots]^{31}$

Páginas atrás, Valdés alude a La Celestina a propósito del decoro. Define el término y, acto seguido, aclara:

VALDÉS. [...] Es propio este vocablo de los representadores de las comedias, los quales entonces se dezía que guardavan bien el decoro, quando guardavan lo que convenía a las personas que representavan. ${ }^{32}$

Sin duda, Valdés hace referencia a las comedias latinas, género en el cual no incluyc a La Celestina, no obstante que el término decoro lo aplica a ésta y a aquéllas. Escrupulosos del léxico, Vives y Valdés reproducen el término tragicomedia sin

31 Juan de Valdés, Diálogo de la lengua, 1984, p. 175.

32 Torres Naharro define así el decoro cn su "Prohemio" a la Pmpalladia (primera poctica española modema, que norma el naciente géncro de la comedia); dar "a cada uno lo suyo", es decir, tratar adecundamente a cada caracter, inspirandole acciones apropiadas y armónicas con un fondo trisic o alegre. Las obscrvaciones de Valdés sobre el tcma no entran en conflicto con csta definición, carcntc de implicaciones moralcs. 
asimilar la obra de Rojas a ningún género clásico. Ambos humanistas, hay que notarlo, fucron expertos compositores de diálogos puros. Quicro decir con todo esto que ellos o Lope mismo obscrvaron en la Celestina su esencial dialogismo tragi-cómico, sin dejar de ver por eso cl carácter literario de la obra o su innegable disposición dramática. Pero de cualquier manera que se mire, el nuevo título elegido por Rojas no pudo ser más elocuente.

\section{Anfitrión según la traducción de Villalobos}

Hasta ahora, los críticos no han observado ninguna relación entre estos dos acontecimientos literarios: la composición en prosa del primer diálogo castellano -llamado Tragicomediacon ascendencia y características dramáticas y la primera traducción al castellano de una comedia romana -única tragicomedia clásica-, traducción prosaica del verso latino. La naturaleza tragicómica de ambas obras, el carácter original de los textos de Rojas y Villalobos, el uso de la prosa castellana ${ }^{33}$ en forma de diálogo y aun la cercanía temporal de sus primeras versiones impresas (1499-1515) son correspondencias entre $L a$ Celestina y la traducción de Anfitrión que merecen ser explicadas. Consecuentemente, destaco en las observaciones siguientes los aspectos de la traducción de Villalobos que de una u otra manera dialogan con la obra de Rojas.

En 1543, cuando Villalobos tenía sctenta años, según él mismo lo anota, publicó un volumen miscelánco con esta portada: "Libro intitulado Los Problemas de Villalobos, que tracta

${ }^{33} \mathrm{La}$ importancia que los dramaturgos españoles dicron al uso de la prosa en la composición de comedias puede nolarse en los comentarios, ya señalados, de Juan Timoneda a la obra de Rojas o cn las características celestinescas de algunos dramas y novelas de Jerónimo de Salas Basbadillo. Véase Lida. La originalidad. p. 57 y n. 21 
de cuerpos naturales y morales, y dos diálogos de medicina, y El Tractado de las tres grandes, y una Cancion, y la Comedia de Amphytrion", Juan Picardo, Zamora, 1543. El volumen contiene un epígrafe de interés para nosotros: "La comedia de Plauto, llamada Amphytrion, que traduzia el doctor Villalobos. La qual glosó él en algunos passos obscuros. Agora nucvamente impressa: vista y emendada por el mismo author". Más adelante, en cl Proemio que Villalobos dirige a GarciFernández Manrique, aparece un dato con el cual sc confirma el aviso de "nuevamente impressa", y, también, se allana el problema de la fecha de la edición princeps: el Procmio menciona al padre de Garci-Fernández, muerto en 1515, como alguien que está vivo. Más todavía, la carta que pone fin a las Sentencias, las cuales son un tratado a propósito de la última cscena de Anfitrión, сіегтa así: "De Calatayud, en 6 de octubre de 1515 años". Moratín menciona (cn Origenes del teatro) una cdición de Zaragoza, de 1515; cn el catálogo de su biblioteca, Salvá dice que le parece haber visto una edición de Alcalá, de 1517, editada por Amao Guillén de Brocar en cuarto y con caracteres góticos. ${ }^{34} \mathrm{Si}$ en razón de los datos anteriores consideramos el año 1515 como el más seguro para datar la primera edición, debemos suponcr que Villalobos realizó la traducción en un lapso de tiempo relativamente cercano a las primeras edicioncs de La Celestina.

De hecho. Villalobos lleva a cabo dos trabajos sobre cl texto de Plauto, los cuales forman una unidad en los propósitos intelectuales del médico: transladar el verso latino a prosa castellana y sentenciar - como filósofo natural y moral— sobre los pasajes del texto referidos al amor. ${ }^{35}$ La primcra tarea tuvo fi-

34 Véasc Antonio María Fabié. "Prólogo" a Francisco de Villalobos, Algunas obras, 1886, p. 219, asimismo, Webber, "Manuscripts", p. 36 y n. 54.

${ }^{39}$ Un terecr propisito —o una variunte del scgundo- se desprende de las glosas de Villalobos al texto de Plauto. La diversidad de temas desarrollados en dichas glosas permite al médico hacer gala de su competencia como tratadista. Un 
nalidades e interlocutores propios, según se desprende del Proemio:

Tres provechos principales se siguen de la traducion desta comedia: el primero es, que por ella los estudiantes de la poesía entenderán cl latin del Plauto cn Anfirrion, sin docurina de maestro, y no lo tengan en poco [...]. El segundiv es que todos los que quisieren pasar tiempo en leer la comedia, verán en ella qué dioses eran aquellos que adoraba la gencilidad, y cuán lejos de razon y de humanidad se fundaban sus ritos y religiones [...]. El tercero es, quc en esta comedia hay algunos pasos y dichos notables, segun por el discurso della se verán por mi mano nolados en la márgen. 36

A tono con la pretensión didáctico-moralizante de los prólogos de la comedia humanística y del mismo Rojas, la segunda tarea tuvo asimismo finalidades e interlocutores propios,

fragmento del epigrafe de 1543 dice: "I.a qual [la comedia] gloso el en algunos passos obscuros. Agora nucvamente impressa: vista y cmendada por el mismo author". O sea que posiblemente las glosas aparecicron en la edición de 1515, hoy perdida. Este puede ser también el caso de las Sentencias; así entonces, la fecha de 1543 no demosiraría que las obras de Villalobos fueran resonancia cardia de La Celesfina. Desde esta perspectiva, las enmiendas y adiciones efectuadas a la posue por cl médico deben entenderse en buena medida como la prolongación de unos diálogos ocurridos en la Univcrsidad de Salamanca durantc la última década del siglo xy y, cuanto más, los primeros años del siglo xv.

36 Cf. Francisco de Villalobos, Curiosidades bibliográficas, 1950. pp. 461462; en adelante, Villalobos, Curiosidades. Esta edición reproduce la de J. Coci (Zaragoza, 1544). Sal vo las del Sumario de la medicina, no hay ediciones actuales de las obras de Villalobos. Las más recientes son:

-Algunas obras. "Prólogo" de Antonio María Fabié, Madrid: Sociedad de Biblibfilos Españoles, t. XXIV. 1886 [contiene Cartas castellanas. Cartas latinas, Diálogo de Villalobos y su criado, Poeslas. El sumario de la medicina, con un tratado sobre las pestiferas bubas].

-Exiravaganies, Barcelona: Biblioteca Clásıca Española. 1884 [contienc e] "Tráclado de las tres grandes" y la "Declaración pucsia á la postrera cena y capitulo de la comedia cl Anfitrión"].

- Los problemas de Villalobos, que iracia de cuerpos naturales y morales; y' dos dialogos de medicina, y el traciado de las ires grandes, y una cancion, y la comedia de Anfitrion, en Curiosidades bibliograficas, Madrid: Atlas. 1950 (B1blioteca de Autores Españoles, vol. 36). 
así el Prólogo a las Sentencias, hechas para la "declaracion de la postrera cena y capítulo desta comcdia" (Villalobos, Curiosidades, p. 487):

El traslador delia pone aquí ciertas sentencias provechosas para la doctrina y enseñamiento de los mancebos, por cuanto van allegadas al estilo dellos y a su manera de vivir [...]. Mas quicro en servicio de la virtud hacer este tratado breve, como diezmo de otras escrituras que yo tengo hechas en servicio del mundo y de la vanagloria.

En la carta que cierra las Sentencias, Villalobos adapta cl tópico didáctico-moralizante aludido a su personal resentimiento con el mundo cortesano, particularmente proclive al trato erótico (Villalobos, Curiosidades, p. 493):

Con las liviandades de Júpiter. como con plumas de gallo, he pescado aquí galanes como truchas, para metellos en la santa doctrina del amor virtuoso: y maguer que ellos se congojarán en salir de sus piélagos, no deja por eso de ser buena la pesca. Esto les doy en pago de cuantas mercedes y favores en esta corte me hacen, porque estoy de voluntad, si Dios quisiere, de dejarlos muy presto.

Traducir a Anfitrión y sentenciar sobre el amor cortesano son dos tareas de un solo propósito tan caro a Villalobos que con seguridad metió la pluma en la última escena de la obra, solapando su autoría en un epígrafe anfibológico y extraño a Plauto, como la escena toda: "Complimiento de la comedia, sacado de otro original". Poniendo fin a la fábula de Hércuics, dicha escena introduce el tema de los cclos, es decir, sirve de eslabón entre el texto traducido y las Sentencias. Pero si algo llama la atención es su hechura a un tiempo groscra y cómica, propia de los bajos fondos cclcstinescos. La siguiente comparación ilustra notables correspondencias entre los textos, 
desde el tono y la relación amo-criado hasta la solución risible, la cual está antecedida por un aserto serio y capcioso (cuyo tema es el intcrcambio erótico humano-divino), y está mcdiada por una interlocución interrogativa:

SOSIA-Señor, si tu has de cumplir con mi ama por la medida Júpiter, gran trabajo tienes.

ANFITRION- ¿Por qué?

ALCUMENA-Cállate, matvado, no digas más.

ANFTTRION-Déjale decir, mujer, porque no lo vaya á decir en la calle. -Di por qué, Sosia.

SOSLA-Porque los dioses tienen recios los lomos, y nunca cansan los inmortales.

ANFITRION-Ah, ah, ah.
SEMPRONIO-[...] no pensava que havía peor invención de pecado que en Sodoma.

CALISTO- ¿Cómo?

SEMPRONIO-Porque aquellos procuraron abominable uso con los ángcles no conoscidos, y tú con el que confiessas ser Dios.

CALISTO-¡Maldito seas! Quc fecho me has reyr, lo que no pensé ogaño (La Celestina, I, 222.)

Otras correspondencias entre la traducción de Villalobos y la obra de Rojas van más allá de la cscena apócrifa del médico, la que sirve a éstc, como ya dijimos, para imbricar su breve tratado sobre el amor con la obra traducida.

Después del Proemio y antes del Argumento gencral, Villalobos introduce una nota aclaratoria:

Aqui se vuelve de latin en romance la primera comedia de Plauto, cuyo nombre es Anfitrion. La trasladacion es fielmente hecha, sin añadir ni quitar, salvo el prólogo que el poeta hace en nombre de Mercurio, y sus argumentos, que esto era bueno para representar la comedia en público y haccr farsa della, porque los miradores entendiesen bien los pasos todos. Aqui no se pone aquello, porque scria cosa desabrida y sin gusto. Bastan los argumentos que yo pongo. porque dan mejor á entender la comedia y son mas sabrosos para los leyentes. 
Con toda claridad se difcrencia el hecho de representar una comedia (hacer farsa della para los miradores) del acto de leer un impreso. Sabemos que el teatro modemo no existía aún en España; sus rudimentos consistían cuanto más en escenificar autos y églogas. También sabemos que los estudiantes universitarios lcían en voz alta, sin representarlas cabalmente, comedias latinas. El problema reside en aclarar lo que Villalobos entiende por leyentes. La cuestión no carece de importancia. Investigaciones recientes sobre la transmisión literaria coinciden en que la práctica común, por lo menos hasta cl siglo xvu, consistía en que un lector más o menos diestro en el manejo de la voz y el gesius leyera en voz alıa tal o cual texto para un público de plaza, aula o salón cortesano. Tan arraigada estaba la costumbre, que en numerosas obras españolas de los siglos xV a XVIl (todavía compuestos en función de las expectativas de su transmisión oral) los términos leer y ofr son sinónimos. ${ }^{37}$ Lo mismo ocurre en el Prólogo de Rojas; ahí donde se observa que la obra ha sido "instrumento de lid o contienda a sus lectores para ponerlos en differencias", sc cstá pensando en lectores que 'oyen', pucs ellos mismos aparecen en forma de auditorio líneas abajo: "Assí que, quando dicz personas se juntaren a oýr esta comedia...". Los versos acrósticos reproducen idéntica sinonimia: "buscad bien el fin de aquesto que escrivo/ o del principio leed su argumento./Leeldo y veréys [...]. / Desta manera mi pluma se embarga, / imponiendo dichos lascivos, rientes, / atrae los oýdos de penadas gentes [...]". Por su parte, Proaza dedica una estrofa para instruir una lectura oral ejecutada por un lector único ante un público de lectores que oyen (La Celesina, pp. 613-614):

37 Vease Margit Frenk, "Lectores y oidores", Aclas del Séptimo Congreso de la Asociación lnemacional de Hispanissos. 1982, pp. 106 y ss.; asimismo, "Ver, ofr. lecr...", Homenaje a Ano María Barrenechea, 1984, pp. 235-240. Para un plantcamiento del tema a escala curopea y desde una perspectiva antropologica. véase Paul Zumihor, Lo leira y la voz. De la "lizerafura medieval", 1989. 
Dize el modo que se ha de tener leyendo esla [tragi] comedia

Si amas y quieres a mucha atención leyendo a Calisto mover los oyentes, cumple que sepas hablar entre dientes, a vezes con gozo, esperança y passión. A vezes ayrado, con gran turbación. Finge leyendo mill artes y modos. pregunta y responde por boca de todos, llorando y riendo en tiempo y sazón.

La costumbre de la época, ${ }^{38}$ las sinonimias de Rojas y las instrucciones de Proaza nos predisponen a creer que Villalobos supuso naturalmente que una sola voz oralizaría su traducción. ¿Cómo explicar entonces la deliberada omisión de didascalias explícitas en el texto del médico, recurso presente en el original latino? Las didascalias explícitas ${ }^{39}$ (Villalobos

${ }^{38}$ Una carta que el médico envi6 a su amigo Jufre en 1517, la cual pucde considcrarse como una prolongacion "rabelaisiana" de las instrucciones de Pronza, nos recuerda las teatrales costumbres cortcsanas de lecr en voz alta: "Vuestra carta fué vista por los señores del Consejo Real, y fué con solemnidad leyda ante la Majestad de la Serenísima Reina, y á la Señora Camarera con las damas [... ]. Ora mirad quánta fucrça teneys en vuestro officio. que tomamos aca por pasaticmpo de mirar el gesto al que lec vuestra carta, porque haze tantos visages y locuras quantas yczes vos meays cada dia y quantas haceys luchar á la razon con el cuero y days con ella patas arriba". CI. Francisco de Villalobos, Algunas obras, 1886, pp. 9-10: cn adelante, Villalobos, Algunas obras.

En olra epístola, dirigida a Hemán Núnez, el médico alude a la lcctura oral de los estudiosos de tratados científicos: "Assi que sabcmos las materias de que trata el texto, y aquellas mismas haucmos lcydo por el mismo autor en aquellas partes donde la traducçion acertó á no ser errada: y así, cotejando las unas con las otras, como maestros de çifras, sacamos la letra en limpio, mucho mcjor que el griego, que no entiende sino la lengua, y cuanto á la sentencia ninguna cosa le entra de los dicntes adentro" (Villalobos, Algunas obras, pp. 95-103).

${ }^{39}$ Distingo entre didascalias paratextuales (usadas por Terencio) y didascalias explícitas, las cuales Plauto pone en boca de algún personaje que las recila al público en aparte. Tal distinción corresponde al criterio de Rojas y Villalobos, de ahi que las omitan. Estos autores emplean didascalias implícitas, las cuales, inscrtas en cl continuum del diálogo, no instruyen al actor. sino al lecior único. 
las llama argumentos, útiles para representar) están también ausentes en la obra de Rojas porque ésta fue escrita para ser leída, no escenificada. La configuración del espacio, el reparto de voces, el transcurrir del tiempo y diversidad de acciones, si no están implícitos en el diálogo, se hallan acotados en los argumentos de cada acto. En vez de traducir las acotaciones de Plauto, Villalobos escribió para cada escena un argumento cuya función es análoga a la que acabamos de mencionar en el caso de La Celestina. ${ }^{40}$ Los recursos vocales y gestuales propios de todo lector competente evitaron a Rojas y Villalobos la tarea de registrar en sus textos didascalias explícitas. Esto adquiere mayor pertinencia si lo referimos al género de las obras. Los autos de Gil Vicente o las églogas de Juan del Encina son el libreto de un espectáculo teatral incipiente, que, como tal, reclama un actor para cada voz-personaje. En cambio, La Celestina, no obstante su ascendencia y técnicas teatrales, no deja de ser un diálogo de varias voces dramáticas. ${ }^{41}$ Por ello Proaza instru-

${ }^{40}$ Doy un ejemplo donde empalma la omisión explícila de las didascalias con la compostura de un argumento (se trata de la transición del acto II al III. scgún cl critcrio de una edición modema):

Junto con esto siguen ciertas palabras que habla Júpiter con los miradores [espectadores] para cuando se representare la comedia en público; no se ponen aqui, porque no valen nada.

Alcumena, desque su marido fuć á buscar testigos contra ella, se queda quejando muy amargamente de tan gran maldad como su marido le lcvan16; en esto entra Júpiter hecho Anfitrion, y descúlpase de todo lo pasado: al cabo se reconcilian en amistad. y aparejanse los sacrificios.

ALCUMENA, JUPITER...

(Villalobos, Curiosidades, p. 476.)

El traductor omite la primera cscena del terecr acto, la cual aclara la intriga, prescnta proplepsis y abunda en didascalias. Cito las más teatrales de éstas:

JUPITER-Yo soy el Anfitrión... sólo en cuanto llego aquf... cambio de indumentaria. Ahora estoy aqui en alención a vosotros, para no dejaros a medias mieles con la comedia esta... Ahora voy a hablar con Alcumena.

(Plauto. Anjutrión, pp. 88-89.)

$\$$ Entiendo por técnica tcatral el conjunto de recursos destinados a la representación escénica de un texto; por ejemplo. Ia auscncia de voz narrativa, las 
yc la lectura de una sola voz. Dicho de otro modo: cl punto básico de encuentro entre la traducción de Villalobos y La Celestina es el diálogo puro. A partir de éste, el autor anónimo y Rojas dramatizan su composición (incluso la novelan), de ahí el efecto teatral de las instrucciones de Proaza. En la versión castellana de Anfitrión la tendencia es inversa: de una comedia $\mathrm{Vi-}$ llalobos extrae el diálogo, por ello omite las didascalias de Plauto y, a cambio, escribe un argumento para cada escena, lo cual equivale a decir que transfiere al dominio de un lector único el conjunto de órdenes destinadas a cada personaje. ${ }^{42}$

Lo mismo puede decirse de las correspondencias $\mathrm{cn}$ el empleo de un recurso dramático característicamente latino, cl aparte. Todos los apartes de Anfitrión están dirigidos al público; por lo tanto, no generan reacción alguna en el personaje interlocutor. Y puesto que Villalobos traduce literalmente, no es el actor, sino el lector quien debe percibir y subrayar, entonándola por ejemplo, la condición apartada de las voces, ya que ésta no sc halla diferenciada en el texto. Tampoco las ediciones antiguas de La Celestina distinguen los apartes. Hacerlo fue tarea del lector. La diferencia estriba en que el autor anónimo y Rojas crean apartes entreoídos, ${ }^{43}$ lo cual provoca

didascalias motrices (desplazamientos y gestus dc los personajes), las acotaciones tcmporales, la alternancia de diálogos y monólogos, la estructuración en actos, que permilc modificar el virual cscenario. Esta última en cl caso de la Celestina, marcá cn principio, el ritmo de la recitación. Por voz dramática entiendo la acción discursiva de cada personaje dispucsta en el texto.

$\$ 2$ Alfredo Hennenegildo ("El arte celestinesco y las marcas de teatralidad", Incipir, vol. XI, 1991, pp. 127.151) analiza de manera sistcmática las didascalias del Primer Auto de La Celestina. El número y variedad de éstas lo llevan a afirmar que la obra es esencialmente tcatral. Hermenegildo, sin cmbargo, no aborda un problema básico: el diálogo celestincsco es pieza para una sola vor. Todo análisis que deje de lado este problema incurrc en anacronismos.

${ }^{43}$ Ademís de instruir una leclura oral, el apartc en La Celestina sirve para caractcrizar moralmente a los personajes que lo practican: los criados, las prostitutas. Celcstina. En este sentido, cl aparle funciona como lécnica de expresión del decoro de los personajes socialmente inferiores, cs decir, necesariamenle hipncritas. 
en el interlocutor reacciones que al mismo tiempo funcionan como didascalias para el lector ${ }^{44}$ (La Celestina, IV, p. 324):

MELIBEA-Más haré por tu doliente, si menester fuere, en pago de lo sufrido.

CELESTINA $\left(\right.$ Aparte ${ }^{45}$ ¡¡Más será menester y más harás, y aunque no se te agradezca!

MELIBEA-¿Qué dizes, madre, de agradescer?

CELESTINA-Digo, señora, que todos lo agradescemos y serviremos y todos quedamos obligados. Que la paga más cierta es quando más la tienen de complir.

Fácilmente perceptible, este tipo de aparte debe leerse, según Proaza, entre dientes. Villalobos, por cierto, sabía componer en diálogos propios apartes entreoídos de corte celestinesco, los que, para sorpresa nuestra, debían leerse jentre dientes!:

Duque-[ $[\ldots]$ en mi seso estoy de haceros mercedes, como os las he hecho, más por vuestra buena razón que por la física ['medicina'].

Doctor-Tal salud os dé Dios como vos me habéis hecho las mercedes, y aún como me las haréis.

Duque- $¿$ Qué estáis gruñendo entre dientes?

Doctor-Digo, señor, que Dios dé mucha salud á vuestra señoría por las mercedes que me ha hecho y me hará. 46

44 “Algunas de las 'paradojas' más cnigmáticas que han dado fama a la obra [La Celestina] quedan iluminadas - si no explicadas - por la comprensión de la tradición oral que está detrás de la fachada impresa. Por cjemplo. cn las primeras cdicioncs, la falta de acotaciones marginales, de subrayados, de puntuación en el scntido modemo, e incluso de sangrados tipográficos, sólo pueden entenderse en términos de la fuerza oral que todavía posela la palabra, de su capacidad para sugerir la pronunciación y entonación sin ayuda externa." Cl. Gilman, La España, p. 316.

${ }^{45}$ El apane se hace explf́cito en la edición moderna que cito. En las ediciones antiguas de la obra todos los apartes estón implícitos.

${ }^{26}$ Se trata del segundo Diálogo de la medicina (Villalobos, Curiosidades, p. 446). 
No obstante que pertenecen a obras disímbolas, los dos fragmentos citados, por su uso del aparte, por su tema e intención, parecen escritos, valga la expresión, con la misma pluma. Así entonces, tanto en el caso de las didascalias como en cl de los apartes, el designio de una lectura en voz alta ejecutada por un solo lector es recíproco del género diálogo, ya en La Celestina, ya en la traducción de Villalobos.

Observemos una correspondencia más, esta vez en relación con la estructura de las obras. Rojas divide en actos la Comedia y la Tragicomedia; advirtamos, sin embargo, que para él acto y escena son sinónimos, así "El autor a un su amigo":

Y porque conozcáys dónde comiençan mis mal doladas razones acordé que todo lo del antiguo auctor fuesse sin división en un auto o cena incluso...

Los manuscritos de las comedias latinas desconocen la división en actos, ${ }^{47}$ pero no en escenas, cuyo cambio señalan consignando los nombres de los personajes que participan en cada una de ellas. Las ediciones antiguas de La Celestina también dividen la obra consignando la nómina de los personajes que participan en el diálogo; además, encabezan de modo original dicha nómina con el término auto, el cual numeran progresivamente. El problema radica en lo siguiente: casi todos los actos contienen más de una escena, tal como la entendemos hoy. ${ }^{48}$ A este respecto, la explicación de Gilman no carcce de interés: desde el punto de vista del ticmpo, La Celestina es un enorme acto dividido en muchas escenas; a su vez, cada acto divide, no la acción en el sentido usual de la palabra, sino el conti-

47 La división en cinco actos deriva de la cdición que en I500 (en Bolonia) hizo de Anfitrión Juan Bautista Pius (González-Haba, "Introduccion", p. 11).

48 Los autos de Gil Vicentc o las Eglogas de Juan del Encina presentan un número indeterminado de escenas. Es Torres Naharro quien. a la usanza clásica, divide la obra dramática en cinco actos, a los cuales llama jomados, con el sentido de 'descansaderos". 
nuum de la conciencia hablada en el diálogo. ${ }^{49}$ Esta idea no entra en conflicto con cl compromiso de Rojas y sus editores a dividir una obra inaugural a la usanza clásica $y$, al mismo tiempo, presentar un número más o menos moderado de actos (separarla sólo en esccnas con un criterio modemo habría implicado una fragmentación disparatada). Por otra parte, la diferenciación entre acto y escena y el desarrollo del significado modemo de la esta última (la cual tenía el sentido vago de 'pieza de teatro') fucron procesos que la dramaturgia española definió a partir de la segunda mitad del siglo xvi (Lida, $\mathrm{La}$ originalidad, p. 53, n. 16).

Villalobos reproduce literalmente las divisiones del manuscrito latino, ${ }^{50}$ pero enfatiza la separación en escenas encabezándolas con sendos argumentos escritos por él. Es decir, estructura el texto de manera semejante a La Celestina, pues los argumentos compuestos para cada escena tienen análoga distribución y la misma función que los argumentos introductorios de cada acto en la obra de Rojas. ${ }^{51}$ Ésta y la traducción de Villalobos contienen asimismo un argumento general, de abolengo terenciano.

La traducción libre de Femán Pérez de Oliva, dedicada a su sobrino Agustín de Oliva, tampoco estuvo destinada a la representación teatral, sino a impartir una lección práctica de retórica al joven pariente y demostrar que cl castellano era apto

${ }^{49} \mathrm{Cf}$. Stephen Gilman, La Celestina: arte y estructura. 1982. pp. 144-145. En adclante. Gilman, Ia Celestina.

${ }^{50}$ La traducción de Pérez de Oliva y la Comedia de Anfitrión (1559) de Juan Timoneda desconocen la división en actos.

31 En su Prólogo. Rojas escribe que "aun los impressores han dado sus punturas, poniendo rubricas o sumarios [argumentos] al principio de cada auto, narando en breve lo que dentro contenia -una cosa bien cscusada según lo que los antiguos scriptorcs usaron". IEn efecto, los comediógrafos latinos no encabezaban las escenas con argumentos individualcs. Por cllo cs significativo que Villalobos st lo haya hecho. En cuanto al problema de la autoría de Rojas respecto de los argumentos de los actos interpolados en la Tragicomcdia, véase Gilman, la Celestina. pp. 327 y ss. 
para expresar una fábula dramática. Lo mismo que Nebrija ("Terentius est summus orator"), advirtió la semejanza del diálogo de la comedia y la oratoria: "Las comedias antes escritas fueron fuentes de la clocuencia de Marco Tulio, que mucho amó su muy familiar Tercncio". En el Prólogo a la Muestra de la lengua castellana en el nacimiento de Hercules - Comedia de Amphitrion, Pérez de Oliva subraya, como Proaza, los tonos orales contenidos en el diálogo cscrito; o sea que instruye a su modo otra lectura en voz alta:

El estilo de deçir en comedia es tan diverso como los mouimientos de los hombres. A veces vá tibio, y á veces con hervor. unas con odio y otras con amor, graues algunas veces, y otras gracioso; unas veces como historia, otras como razonamiento y otras veces es habla familiar (Fabié, "Prólogo", p. 169).

Gilman (La España, p. 317) ve en estas observaciones una incertidumbre correlativa a las instrucciones de Proaza, portavo $z$ de Rojas: la confianza en la capacidad oral del diálogo escrito termina cuando éste se abandona a lectores desconocidos, para quienes las palabras dejan de poseer la fuerza mágica de poder hablar por sí mismas; sólo entonces comienzan a preguntarse los autores por la utilidad de hacer algunas indicaciones acerca de la locución. Pienso que Gilman no acierta, pues la expresividad de la voz cra hasta entonces patrimonio de todo hablante, y su retórica, recurso por excelencia de lectores profesionales de manuscritos o impresos, los cuales delcgan cn el lector avisado —dadas sus omisiones- la ejecución más o menos discrccional de modulaciones vocales y gestuales. La inquietud de Rojas, Proaza o Pérez de Oliva proviene, supongo, del carácter de los textos que cscriben (Rojas afirma en los versos acrósticos que la obra "terenciana" del autor anónimo es única "en lengua común vulgar castellana"). Esto es, proviene de la novedosa inclusión en lengua española de diálogos con ascendencia y perfil dramático, destinados, por 
estar impresos, a un público extrauniversitario. De ahí que las instrucciones se orienten a normar en una sola voz "el estilo de deçir en comedia".

Pérez de Oliva fue a la postre catedrático de Filosofía y Tcología en la Universidad de Salamanca. Llegó a esta ciudad en 1508, cuando tenía catorce años de edad. Su traducción fue publicada hacia 1525. Las fechas lo alejan del diálogo que he venido argumentando; en consecuencia, la fluidez coloquial de su texto, observada por Gilman, y las correspondencias entre su Prólogo y los versos de Proaza podemos ahora sí explicarlas como influencia externa de La Celestina sobre esa segunda traducción de Anfitrión. Y aun si no se toma en cuenta lo dicho hasta aquí, parecc improbable que Rojas adquiricra en Talavera de la Reina la traducción dc un desconocido - Pércz de Oliva - a sus, digamos, cincuenta años de cdad.

El intercambio discursivo propuesto entre la obra de Plauto, la versión de Villalobos y La Celestina pretende reconstruir el papel que la tragicomedia latina tuvo en los diálogos de y entre Rojas y Villalobos. Eco permanente de éstos, memoria silenciosa y tangible habría sido el libro de Plauto traducido por el médico, el cual Rojas conservó hasta la muerte en su modcsta biblioteca (modesta quizá por selectiva), donde no quiso alojar el bachiller las comedias de Terencio, ni otras obras en diálogo (salvo la Propalladia), ni siquiera nuevas ediciones de La Celestina o los títulos de sus continuadores.

Útil imprescindible, Anfitrión habría animado las varias voces de un hipotético taller donde lo mismo se componían los consabidos remedios contra el amor (bajo la forma de carta, de verso acróstico o de escena apócrifa, la cual endosa Villalobos a Plauto), que los tragicómicos amoríos de Calisto y Melibea o el traslado al castellano de la única tragicomedia latina. 


\section{Bibliografia}

ARISTÓteles, Poética, introducción y ed. trilingüe de Valentín García Yebra, Madrid: Gredos, 1992.

BarTlN, Mijaíl M.. "Para una reelaboración del libro sobre Dostoievski", en Estética de la creación verbal, trad. de Tatiana Bubnova, México: Siglo XX1, 1982, pp. 324-345.

_- La cultura popular en la Edad Media y en el Renacimiento, trad. de Julio Forcat y César Conroy, Madrid: Alianza Editorial, 1987.

Castro Guisasola, Francisco, Observaciones sobre las fuentes literarias de "La Celestina", Revista de Filología Española, Anejo V, Madrid, 1924.

Cervantes SaAvedra, Miguel de. El ingenioso hidalgo don Quijote de la Mancha, I, ed. de Luis Andrés Murillo, Madrid: Castalia, 1987.

Covmratrias, Sebastián de, Tesoro de la lengua castellana o española, ed. facs., Madrid-México: Turner, 1984.

Fabrf, Antonio María, "Prólogo" a Francisco de Villalobos, Algunas obras, Madrid: Sociedad de Bibliófilos Españoles, 1886.

Frenk, Margit, "Lectores y oidores", Actas del Séptimo Congreso de la Asociación Internacional de Hispanistas, vol.1, Roma: Bulzoni, 1982. pp. 101-123.

—. "Ver, oír, leer...", Homenaje a Ana María Barrenechea, Madrid: Castalia, 1984, pp. 235-240.

Garcla Yebra, Valentín, "Introducción" a Aristóteles, Poética, Madrid: Gredos, 1992, pp. 7-124.

Gilmax, Stephen, La España de Fernando de Rojas. Panorama intelectual y social de "La Celestina", trad. de Pedro Rodríguez Santidrián, Madrid: Taurus, 1978 [Ia. ed. Princeton University Press, 1972].

—. La Celestina: arte y estructura, trad. de Margit Frenk, Madrid: Taurus, 1982 [1a. ed. The University of Wisconsin, 1956].

González-Haba, Mercedes. "Introducción" a Plauto, Comedias, I, Madrid: Gredos, 1992, pp. 7-32. 
Hatbl.t. Conrado, Bibliografía ibérica del siglo xv, La Haya: Martinus Nijhoff/ Lcipzig: Karl W. Hicrsemann, 1903.

Hi:rafenfgildo, Alfredo, "El ante celestinesco y las marcas de icatralidad", Incipit, XI, 1991, pp. 127-151.

J'MENEY DE. URREA, Pedro Manuel, Penitencia de amor (Burgos, 1514), ed. de Raymond Foulché-Delbosc, Barcelona-Madrid: Bibliotheca Hispanica, 1902.

LIDA de Mal.kiel, María Rosa, La originalidad arrística de "La Celestina", Buenos Aires: Eudeba, 1970.

Plauto, Comedias, I, introducción, traducción y notas de Mercedes González-Haba, Madrid: Gredos, 1992.

Rouas, Fernando de, Comedia o Tragicomedia de Calisto y Melibea, ed. de Peter E. Russell, Madrid: Castalia, 1991.

_- Tragicomedia de Calixto y Melibea, ed. facsimilar de la hecha en Valencia en 1514, Madrid: Espasa-Calpe, 1975.

Russell, Peter E., "La magia, tema integral de La Celestina", en Temas de "La Celestina" y orros estudios (del "Cid" al "Qujote"), trad. de Alejandro Perez, Barcelona: Ariel, 1978.

- "Introducción" a Femando de Rojas, Comedia o Tragicomedia de Calisto y Melibea, Madrid: Castalia, 1991, pp. 11-178.

Valdes, Juan de, Diálogo de la lengua, ed. de Juan M. Lope Blanch, Madrid: Castalia, 1984.

Vals.e Lersundi, Fernando del, "Testamento de Fernando de Rojas, autor de La Celestina", Revista de Filología Española. XVI, 1929. pp. 366-388.

VEGa y CARpIO, Félix Lope de, Novelas a Marcia Leonarda, Obras escogidas, e. II, estudio preliminar, notas y apéndices de Fedcrico C. Sáinz de Robles, Madrid: Aguilar, 1961.

—. Are nuevo de hacer comedias, en Obras escogidas, t. II.

Villalobos, Francisco de, Algunas obras, prólogo de Antonio María Fabié. Madrid: Sociedad de Bibliófilos Españoles, 1886.

—- Extravagantes. Barcelona: Biblioteca Clásica Española, 1884.

_- Los problemas de Villalobos, que tracta de cuerpos naturales y morales; y dos diblogos de medicina, y el tractado de las tres grandes, y una cancion, y la comedia de Anfitrion, en Curiosidades bibliograficas. Madrid: Atlas, 1950 (Biblioteca de Autores Españoles, vol. 36). 
Werber, Edwin J., "Manuscripts and Early Printed Editions of Terence and Plautus in Spain", Romance Philology, XI, 1, 1957, pp. 29-39.

Zumrhor, Pall, La letra y la voz De la "Literatura medieval", trad. de Julián Presa, Madrid: Cátedra, 1989 [1a. ed. París: Seuil, [987]. 


\section{En este número colaboraron:}

Ainaud, Jordi. Profesor de traducción de la Universidad de Pompeu Fabre en Barcelona. Es traductor de francés, inglés, catalán y español en varias editoriales reconocidas. Ha publicado en revistas especializadas. Cursó el doctoradc en Literatura Medieval en la Universidad de Londres.

Armiso, Carmen. Investigadora del Seminanio de Poética del IIFL. Profesora de Literatura Española Medieval en la FFyL, UNAM. Ha publicado diversos artículos sobre El libro de los gatos.

Azuela, Cristina. Doctora por la Universidad de la Sorbona, Francia. Investigadora del Scminario de Poética del Instituto de Investigacioncs Filológicas. Tiene diversas publicaciones sobre literatura comparada medieval, fundamcntalmente sobre la Nouvelle.

BERESFord, Andrew M. Es profesor de Literatura Medieval en la Universidad de Durham (Reino Unido). Se doctoró en Literatura Medieval en la Universidad de Londres. Ha publicado en varias revistas especializadas. Fue editor de la colección Papers of Medieval Research Seminar (Department of Hispanic Studies, Queen Mary and Westfield College, Londres).

BizzarRI, Hugo. Profesor de Literatura Medieval en la Universidad de Bucnos Aires, Argentina. Investigador del Conicet. Se ha especializado en la crítica textual y en colecciones de senten- 
cias. Entre sus publicaciones están: "Pseudo Aristóteles. Secreto de los secretos", "Diálogo de Epicteto y el emperador Adriano", "Diccionario paremiológico e ideológico de la Edad Media".

Bubnova, Tatiana. Doctora en Literatura Hispánica por El Colegio de México. Investigadora del IIFL. Es también traductora de varias obras de Mijaíl Bajtín al español. Entre sus múltiples obras están: F. Delicado puesto en diálogo: las claves bajtinianas de La lozana andaluza, Contrapunto a cuatro voces en los caminos del aire.

CÁndano Frerro, Graciela. Doctora en Letras Españolas por la UNAM. Investigadora del IIFL. Profesora de Litcratura Española Medieval de la FFyL, UNAM. Su área de investigación es la literatura ejemplar. Entre sus obras están: Estructura, función y desarrollo de las colecciones de exempla en la España del siglo $x$ xI, La seriedad y la risa (La comicidad en la literatura ejemplar de la Baja Edad Media), La harpía y el comudo (Visión de la mujer en la literatura ejemplar de la Baja Edad Media española).

GARCia de LA Stenra, Rodrigo. Rcalizó la licenciatura en Lengua y Literatura Hispánicas de la UNAM. Fue becario del Proyecto "Poesía y Cultura Popular Novohispana". Actualmente realiza el doctorado en la Universidad de Montpellier, Francia.

González, Aurelio. Doctor en Literatura Hispánica por El Colegio de México. Profesor de Literatura Española Medieval y de Literatura de los Siglos de Oro en la FFyL, UNAM. Tiene diversas publicaciones sobre la tradición oral, el romancero y los libros de caballerías.

González OCHOA, César. Investigador del Seminario de Poética del Instituto de Investigaciones Filológicas (IIFL), UNAM; actualmente se ocupa de lo referente a la historia de la cultura. Entre sus libros están: La música del universo. Apuntes sobre la 
noción de armonía de Platón, $A$ lo invisible por lo visible. Imágenes del Occidente medieval.

ILLADES, Gustavo. Doctor en Literatura Española por la FFyL, UNAM. Entre sus publicaciones están: El discurso crítico de Cervantes en El cautivo, y La Celestina en el taller salmantino.

Masera, Mariana. Es investigadora del Seminario de Poética del Instituto de Investigaciones Filológicas de la UNAM, donde investiga "La canción tradición mexicana, una poesía olvidada: poética y cntorno". Ductorada en literatura medieval por la Universidad de Londres. Ha publicado en varias revistas internacionales. Entre sus obras está "Que non dormiré sola, no": La voz femenina en la antigua lírica tradicional hispánica.

Pedrosa, José Manuel. Es profesor de Teoría de la Litcratura y Crítica Literaria de la Universidad de Alcalá (Madrid). Ha publicado unos ciento treinta artículos en Filología y Antropología en diversas publicaciones especializadas. Entre sus publicaciones están Las dos sirenas y otros estudios de la literatura tradicional, El cancionero de las montañas de Liébana, etcétera.

Rubial, Antonio. Doctor en Historia por la Facultad de Filosofía y Letras (FFyL), UNAM y doctor en Filosofía y Letras por la Universidad de Sevilla. Profesor titular de Historia Medieval e Historia Novohispana en la FFyL, UNAM. Autor de varios libros, entre ellos: La santidad controvertida, La hermana pobreza, Los libros del deseo.

Thomasset, Claude. Profesor en la Universidad de la Sorbona, Francia. Ha escrito numerosos libros sobre literatura medieval, entre los que se cuenta: Sexualidad y saber médico; y colaboró además en el libro Historia de las mujeres. La Edad Media, dirigido por Georges Duby. 
Acta Poesica 20.

editado por el Instituto de Investigaciones Filológicas, siendo jefe del departamento de publicaciones Sergio Reyes Coria. se terminó de imprimir en los talleres de Trazo Binario, el día 9 de octubre de 2000. La composición, en tipos Times 12:14, 10:12 y 9:10, fue elaborada por Carolina Olivares Chavez y estuvo al cuidado de Graciela Cándano Fierro, con la colaboración de Maribel Madero Kondrar. La edición. impresa en papel cultural de $60 \mathrm{~kg}$, consta de 500 ejemplares. 